\title{
ACCESIBILIDAD Y PROVISIÓN DE SERVICIOS DE INTERÉS GENERAL EN LAS ÁREAS RURALES DE LA UNIÓN EUROPEA: UN ANÁLISIS A PARTIR DEL EUROBARÓMETRO ${ }^{1}$
}

\author{
Joan Noguera Tur \\ Adrián Ferrandis Martínez \\ Departamento de Geografia. Universitat de València \\ joan.noguera@uv.es, adrian.ferrandis@uv.es
}

\section{RESUMEN}

La finalidad de este trabajo es ofrecer un estado de la cuestión sobre el acceso y provisión de Servicios de Interés General (SeIG) en las áreas rurales de la Unión Europea. Se identifican fuerzas de cambio, oportunidades y dificultades relativas a los SeIG que pueden contribuir a impulsar o ralentizar los procesos de desarrollo rural. Se lleva a cabo una revisión de las principales aproximaciones teóricas y se presentan diversos análisis empíricos a partir de los escasos datos homogéneos disponibles. A partir del conocimiento adquirido se formula un conjunto de reflexiones sobre la función de los SeIG en los procesos de cambio rural en la UE.

Palabras clave: áreas Rurales, Desarrollo Rural, Servicios Públicos y Desarrollo Sostenible.

Fecha de recepción: abril 2012.

Fecha de aceptación: julio 2013.

1 El contenido de este artículo emana de los resultados del proyecto EDORA (European Development Opportunities for Rural Areas), perteneciente al programa ESPON 2013 y llevado a cabo entre septiembre de 2008 y diciembre de 2010. En él han participado, además del Instituto de Desarrollo Local (Universitat de València), las siguientes instituciones: Nordregio (Suecia), von Thunen Institute (Alemania), University of Newcastle (Gran Bretaña), University of the Highlands and Islands (Gran Bretaña). 


\begin{abstract}
The aim of this paper is to present a state-of-the-art analysis of the provision and access to Services of General Interest (SGI) in rural areas of the European Union. This analysis aims at identifying SGI-related drivers of change, opportunities and constraints that either promote or hinder rural development. The paper reviews various theoretical approaches and carries out empirical analyses that help to understand the dynamics and state of SGI in rural areas. On this basis, policy recommendations regarding the future of SGI are formulated.
\end{abstract}

Key words: Rural areas, Rural Development, Public Services and Sustainable Development.

\title{
I. INTRODUCCIÓN
}

A lo largo de la historia sólo las ciudades han sido capaces de proporcionar de manera sostenida un rango amplio de servicios públicos. Los espacios rurales, por el contrario, han carecido de la capacidad para poner en marcha y/o sostener muchos de estos servicios, lo que hacía necesario recorrer grandes distancias, físicas o en tiempo, hasta el punto de provisión más próximo. En consecuencia, el modo de vida rural se encontraba más aislado del resto de la sociedad y era considerado más «primitivo» que el estilo de vida «moderno» de las ciudades (Labasse, 1973).

A pesar de que se mantiene un importante diferencial en el nivel de provisión y acceso a servicios entre lo urbano y lo rural, los tiempos han cambiado. Especialmente a partir del final de la Segunda Guerra Mundial, las sociedades europeas experimentan un proceso de crecimiento económico y modernización social sin precedentes. En el caso de las democracias de Europa occidental, el despliegue de servicios universales y la provisión estandarizada de infraestructuras trajeron consigo avances básicos pero fundamentales para las áreas rurales que, muy probablemente, nunca hubiesen alcanzado a las áreas más inaccesibles o menos pobladas en un sistema de producción puramente basado en el mercado (Moseley, 1979; Camarero, 1993). Por otro lado, los regímenes comunistas de la Europa oriental extendieron la idea de proletarización a las áreas rurales a través de procesos de industrialización. Ello supuso un legado de equipamientos, servicios y saber hacer en amplios espacios rurales de los Nuevos Estados Miembros (NEM) (Palang et al., 2006). Estos procesos han facilitado la expansión de servicios públicos y privados tanto en los espacios urbanos como en el mundo rural. En la actualidad, y a pesar de los persistentes problemas que aquejan a un buen número de territorios rurales, principalmente los más inaccesibles, la mayoría de las regiones rurales Europeas disfruta de niveles de provisión y accesibilidad a servicios inimaginables, incluso en ciudades, tan sólo 50 años atrás.

Existen varios motivos por los que la Unión Europea presta especial atención a algunos servicios. En primer lugar, el acceso a servicios entronca con uno de los principales objetivos de la política europea; la cohesión territorial. Tal como apunta la Comisión Europea en su Libro Verde sobre los Servicios de Interés General (SeIG) (2002): «dado su peso en la economía y su importancia para la producción de otros bienes y servicios, la eficiencia y cali- 
dad de estos servicios (SeIG) constituye un factor para la competitividad y mayor cohesión, especialmente en lo que respecta a la atracción de inversión por parte de las regiones más desfavorecidas» (Comisión Europea, 2002:5). En segundo lugar, se considera que el acceso a determinados servicios es un elemento central de la calidad de vida, y la mejora de la accesibilidad a los mismos, un mecanismo para superar la exclusión social y el aislamiento. Por tanto, los SeIG «conforman un elemento esencial del modelo Europeo de sociedad» (ibid:5). En tercer lugar, la cuestión de los SeIG afecta al debate sobre la función que deben tener las instituciones públicas en sociedades comprometidas tanto con el libre mercado como con objetivos sociales. ¿Qué grado de libertad, regulación o provisión pública de servicios debe perseguirse? Por otro lado, nos encontramos con el debate sobre la provisión pública o privada de servicios (ej. eficiencia en la utilización de recursos públicos, riesgo de «mercantilización», etc.) y el modo en que este debate se plasma en el caso de las áreas rurales donde la rentabilidad es, con frecuencia, más que dudosa.

Por todas estas razones los SeIG se encuentran en el centro del debate político, en especial por lo que respecta al futuro de las áreas rurales europeas (Noguera y Morcillo, 2012).

\section{OBJETIVO Y ENFOQUE METODOLÓGICO}

El objetivo del presente trabajo es establecer una definición de los SeIG y caracterizar el estado de su provisión y calidad en el ámbito de las regiones rurales de la Unión Europea. Para ello se ha recurrido, en primer lugar, a una revisión de la bibliografía especializada y, posteriormente, a la detección y análisis de la información estadística disponible sobre SeIG a escala europea. Aunque son numerosos los estudios sobre SeIG en Europa, la mayoría se refiere a un solo tipo de servicio, un país, política o programa específico. Apenas hay estudios dedicados a los SeIG en las zonas rurales de Europa. Es por ello que se ha recurrido a algunos informes basados en Eurobarómetros en los que se han añadido preguntas relacionadas con los SeIG (Eurobarómetro EB 47.0 (1997), EB 53 (2000), 58,0 (2002), EB 62.1 y EB 62.2 (2004), EB 63.1 (2005) y EB 65.3 (2006)). De ellos, sólo el EB 47.0 y el EB 62.1 y 62.2 ofrecen un grado suficiente de compatibilidad tanto en términos de cobertura como de metodología. En consecuencia, el análisis se centra en estos dos Eurobarómetros.

\section{PRINCIPALES APROXIMACIONES TEÓRICAS A LA DEFINICIÓN Y PROVISIÓN DE LOS SEIG}

En sentido amplio, el término «SeIG» se refiere a lo que se ha venido en llamar «servicios públicos». Se denominaron «públicos» porque, durante siglos, servicios como las escuelas, hospitales, carreteras, servicio postal y de comunicaciones, etc., fueron proporcionados casi exclusivamente por autoridades e instituciones públicas. Sin embargo, con la llegada de procesos de privatización a gran escala de estos servicios, el concepto «servicio público» tradicional quedó en cuestión (Banister y Berechman, 2000; Nutley, 1992). Por otro lado, a pesar de que algunos de estos servicios son actualmente ofrecidos por compañías privadas, existen diferencias de base ya que, por ejemplo, servicios como los de atención hospitalaria, tienen connotaciones claramente diferentes de otros servicios privados como el comercio minorista. En este caso, la finalidad de la provisión es el consumo privado no vital, mientras que en el caso del hospital, se trata de una provisión esencial para la salud y bienestar de los 
ciudadanos y de la comunidad. Por tanto, lo «público» tiene un interés especial en ciertos servicios (principalmente aquellos que pertenecen o solían pertenecer al dominio público) que, en consecuencia, se denominan «SeIG» (Muscar, 2008).

El concepto de SeIG se utiliza en todos los documentos estratégicos de la Unión Europea en el ámbito de los servicios. De este modo, la UE adopta una posición neutral hacia la cuestión de la naturaleza pública o privada del prestatario, al tiempo que se reafirma en que ciertos servicios tienen una importancia particular para la calidad de vida de los ciudadanos y el funcionamiento de las economías europeas (COM, 2003; COM, 2004a; COM, 2008a; COM, 2008b). Por tanto, los SeIG incluyen todos los servicios que se considera que se prestan por el interés general de la sociedad y que, por tanto, están sujetos a las obligaciones del servicio público. El concepto de SeIG incluye los denominados «servicios ajenos al mercado» como la educación, seguridad o justicia. En todo caso, también puede producirse una privatización en estos servicios. Sin embargo, se distinguen de los «servicios de interés económico general» (SeIEG) que se refieren a servicios comerciales sobre los que recaen obligaciones específicas del servicio público (COM, 2006b). En este caso hablamos de los servicios de transporte, la provisión de energía y los servicios de (tele)comunicaciones. Dado que los límites que separan los servicios ajenos al mercado de los servicios económicos son fluidos e, incluso, pueden variar en función del marco nacional de referencia, continuará utilizándose el concepto de «SeIG».

A pesar de estas clarificaciones terminológicas, no existe una definición o «listado» de SeIG en Europa. Incluso los documentos estratégicos de la Comisión Europea sobre este asunto (Libros Verde y Blanco) se quedan cortos a la hora de proporcionar un listado. Por el contrario, se limitan a mencionar de pasada diferentes tipos de servicios en varios pasajes de estos documentos. Puede que esto se deba a una actitud de precaución de la Comisión para no traspasar sus competencias políticas mediante afirmaciones sobre servicios que dependen principalmente de regulaciones nacionales, regionales o locales. Por otra parte, en el contexto de la UE existe tal grado de diversidad en lo que se refiere a hechos culturales, modelos sociales e historias políticas que se hace difícil alcanzar un consenso sobre qué servicios deberían ser considerados «de interés general».

No obstante, con el fin de delimitar someramente los contenidos de este trabajo, se ha procedido a establecer un listado de servicios que podrían, en principio, considerarse como SeIG, a partir de los contenidos de los documentos estratégicos y la literatura académica sobre el tema (Tabla 1).

En clara relación con la provisión y uso de los SeIG se encuentra el concepto de «accesibilidad»; es decir, el vínculo entre los servicios y sus usuarios. La accesibilidad es un concepto multidimensional que incluye aspectos físicos, temporales, económicos y socioculturales (ver figura $\mathrm{n}^{\circ} 1$ ). Obviamente, la infraestructura de transportes y los servicios públicos de transporte son elementos esenciales de la accesibilidad (Vinson, 2004). Yendo más allá, Moseley (1979) define el concepto de acceso en relación con la proximidad del lugar de residencia del usuario a los servicios locales, y con factores subjetivos de movilidad. En una aproximación sustancialmente diferente, Sarkar y Ghosh (2000) conciben la accesibilidad desde un punto de vista físico, como las dificultades que afronta un individuo para alcanzar la localización de un servicio. Por tanto, vinculan la accesibilidad al grado de movilidad personal y al nivel de implantación y calidad de los servicios. Derek, Farrington y Copus (2002) 
Tabla 1

LISTADO DE SEIG

1. Transporte (carreteras, líneas ferroviarias, puertos, aeropuertos, servicios de transporte intra e inter urbanos)

2. Servicios postales

3. Telecomunicaciones (cable, telefonía fija y móvil, banda ancha, etc.)

4. Servicios de radiodifusión (TV, radio)

5. Provisión de energía (gas, electricidad, gasolinas y gasóleos)

6. Provisión de agua potable y tratamiento de aguas residuales

7. Recogida y tratamiento de residuos sólidos

8. Educación y cuidados preescolares

9. Educación (primaria, secundaria y universitaria)

10. Salud (atención médica y farmacéutica, hospitales)

11. Cuidados gerontológicos (residencias, servicios a domicilio para la tercera edad)

12. Seguridad (policía, ejército, sistema judicial)

13. Ocio y cultura (espacios públicos abiertos, museos, bibliotecas, etc.)

Fuente: Elaboración propia.

Figura 1

LA NATURALEZA MULTIDIMENSIONAL DE LAACCESIBILIDAD

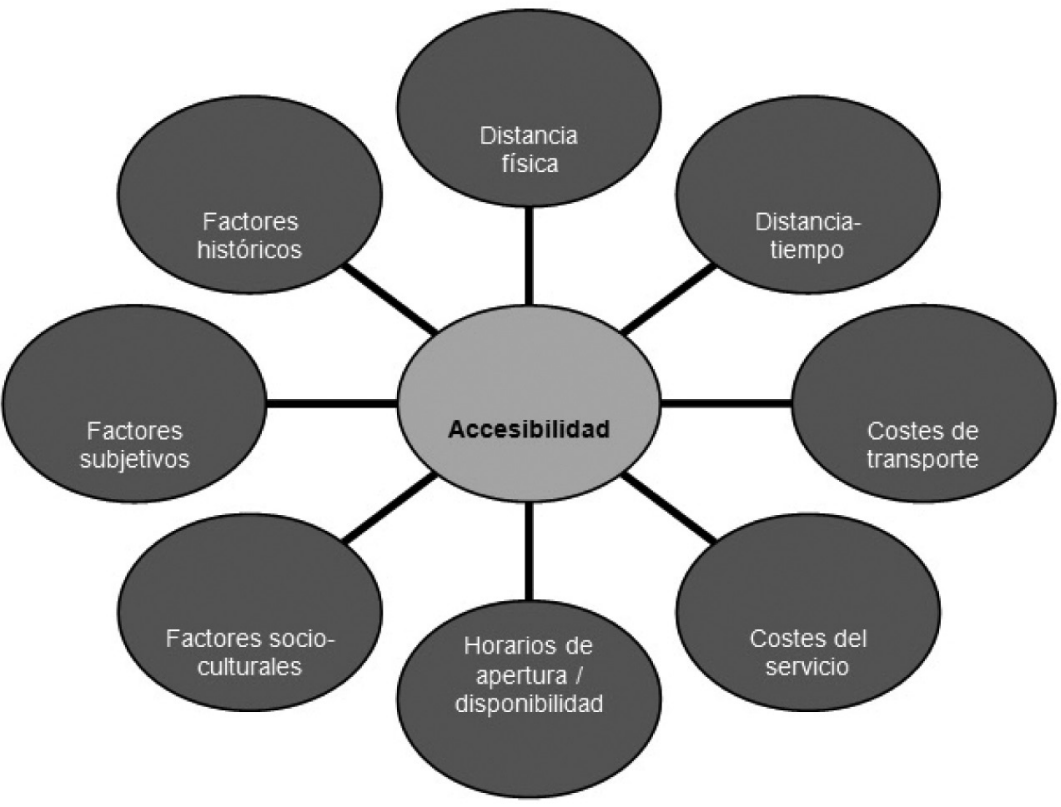

Fuente: Elaboración propia 
asocian la accesibilidad rural a los servicios y equipamientos disponibles, y a las opciones de desplazamiento para alcanzar esos servicios.

Existe cierto consenso en la literatura científica en que el concepto de movilidad posee dos componentes que están en relación con la provisión, acceso y uso de los SeIG: por un lado, un componente objetivo relacionado con la calidad y disponibilidad de infraestructuras y servicios de transporte; por otro lado, un componente subjetivo que agrupa diversas características subjetivas de quienes acceden (minusvalías y condicionantes para la movilidad personal, edad, nivel y disponibilidad de ingresos, culturas de la movilidad, etc.) (Moseley, 1979; Farrington y Farrington, 2005).

Existen igualmente aspectos relacionados con la cultura que condicionan la accesibilidad (por ejemplo, la medida en que ciertos equipamientos y formas de provisión de servicios se consideran apropiados para ser utilizados por distintos perfiles individuales y grupales de forma simultánea). En este sentido, el diseño, las normativas de uso y los horarios de los servicios también afectan al grado de accesibilidad. Por último, el costo del servicio y del transporte necesario para llegar a él, también actúan como condicionantes de su accesibilidad a usuarios potenciales. El coste se convierte con frecuencia en un impedimento principal para la utilización de determinados servicios por parte de los grupos socioeconómicos más desfavorecidos (Alguacil, 2006).

La cuestión de qué servicios son esenciales para el bienestar general de la sociedad y, por tanto, deben ser regulados o provistos por el Estado, ha sido sujeto de debate durante siglos. Subyacen diferentes concepciones teóricas de estos «servicios esenciales». El debate puede relacionarse con el tema general de la cohesión territorial en el que existen teorías contrapuestas sobre el modo en que puede alcanzarse la cohesión y el desarrollo sostenible. Otro conjunto de teorías trata de explicar la mejor localización para diferentes servicios. En muchas de estas teorías aparece el concepto de accesibilidad como un elemento central. Sin ánimo de exhaustividad, se introduce una reflexión sobre algunos de los principales enfoques teóricos que tratan la función de los SeIG.

\section{Los SelG como bienes públicos}

Una primera concepción de lo que hoy en día denominamos SeIG es la de considerarlos como manifestaciones de bienes públicos. Un bien público es lo que los economistas entienden por un bien que puede consumirse sin reducir su disponibilidad (no competitivo) y de cuyo disfruten no puede excluirse a nadie (no exclusivo). Estas dos características hacen que sea poco realista o imposible que dicho bien sea proporcionado por un proveedor privado o comercial. Si no existe escasez de un bien y el acceso a su disfrute no puede controlarse, los mecanismos del mercado no pueden funcionar. Por tanto, los bienes públicos conducen a un «fallo del mercado». Por el contrario, a no ser que existan de forma natural, los bienes públicos solo pueden producirse y ofertarse a través de actores que no se rigen primariamente por el mercado, como es el caso de las autoridades públicas.

Un fenómeno económico relacionado con el anterior y que es responsable de «fallos de mercado» es la denominada «externalidad positiva». Un bien o servicio tiene externalidades positivas si sus beneficios se extienden más allá de los compradores al ámbito de la sociedad general. Por ejemplo, los bomberos no solo extinguen un incendio sino que, mediante esa 
acción, también protegen al entorno urbano inmediato de la expansión de ese fuego. Sin embargo, no todos los vecinos, especialmente si se encuentran alejados del lugar del incendio, estarían dispuestos a pagar el coste de la extinción del fuego, a pesar de que disfrutan de los beneficios del incendio extinguido. Por tanto, las externalidades positivas evitan que un productor o comprador internalice todos los beneficios de un bien o servicio. Ello disminuiría el incentivo para producir o comprar el bien o el servicio y conduciría, en una situación extrema, a la descomposición del mercado: estos productos o servicios no se producirían en suficiente cantidad o se dejarían de producir, a pesar de su efecto positivo sobre el conjunto de la ciudadanía. Se trata de otra situación de «fallo de mercado» que demandaría de nuevo la provisión pública del bien o servicio.

Con frecuencia se han utilizado estos argumentos como justificación general para proveer servicios públicos. No hay duda que muchos de los servicios públicos que ofrecen las instituciones públicas exhiben las características descritas - por ejemplo, los servicios de bomberos, policía, recogida de residuos, carreteras, parques, hospitales o escuelas, entre otros. Pero el argumento de los bienes públicos no es absoluto, incluso en estos casos. Existen hospitales y escuelas privadas, al igual que hay carreteras y vías ferroviarias, que se han construido y son operados por manos privadas. Y en los últimos años, encontramos servicios que son ofrecidos por el estado pero que claramente no se corresponden con el concepto de servicio público (correos, servicios de telecomunicaciones, provisión de energía). No es, por tanto, sorprendente que esta última categoría de servicios concentre los debates y políticas sobre privatización. Incluso los servicios que se ajustan bien a la categoría de bienes públicos y que son ofrecidos por actores públicos, han sido devorados por los nuevos debates que se basan en diferentes enfoques conceptuales: ¿Qué servicios deben priorizarse en tiempo de haciendas públicas en retroceso y de dificultades presupuestarias? ¿En qué condiciones debe prestarse el servicio público? ¿Es posible afectar los principios de gratuidad y universalidad sin comprometer el estado del bienestar?

\section{El enfoque «centrado en la demanda» de los SelG}

El punto de partida de este enfoque es la concepción de los usuarios de SeIG como clientes. Se asume una relación fundamentalmente económica entre el usuario y el proveedor del servicio. Dicha relación se optimiza cuando el cliente privado es servido por proveedores comerciales. Una consecuencia lógica de este enfoque es que los servicios públicos deben privatizarse. Solo de este modo los mecanismos de mercado pueden regular adecuadamente la oferta y demanda de servicios. Bajo este enfoque, los proveedores no solo se ocupan de atender las demandas específicas y cambiantes de los clientes sino que, además, hay competencia entre proveedores de servicios. Ello asegura, en teoría, una mayor eficiencia, precios más bajos y una mayor calidad de servicios y, en consecuencia, una mayor satisfacción de los clientes.

Por tanto, este enfoque reclama la privatización de los actuales servicios públicos. Es fácil encontrar los vínculos de este enfoque con ideologías neoliberales, orientadas al mercado y que muestran una oposición frontal a la intervención del estado y una preferencia por la propiedad individual. De acuerdo con este enfoque el estado debe evitar limitar el funcionamiento autónomo de los proveedores privados de servicios mediante normas y regulaciones. 
Sin embargo, este enfoque no implica necesariamente privatización. Como parte del paradigma de la Nueva Gestión Pública (NGP), el enfoque «centrado en la demanda» también se refiere a servicios públicos no privatizados. El paradigma de la NGP demanda una reforma del sector público dirigida a mejorar la eficiencia y los resultados. Esto implica la aplicación de conceptos, principios y técnicas de organizaciones del sector privado a las administraciones públicas. El objetivo es transformar la concepción básica de las funciones de los diferentes actores que proveen, usan o regulan los servicios públicos: se considera a los tomadores de decisiones como directivos, a los administradores como gerentes, a los ciudadanos como accionistas, y a los usuarios como clientes. De este modo, los servicios públicos compiten por los clientes, estudian sus preferencias, están atentos a su grado de satisfacción, y ofrecen servicios de forma más eficiente (por ejemplo, a menor coste). Por otro lado, los precios de los servicios tendrían que reflejar los verdaderos costos de producción y, en este sentido, podrían ser más elevados que las tarifas fijadas políticamente.

La NGP y la privatización son fenómenos que pueden darse en paralelo. De hecho, la privatización de servicios públicos puede formar parte de una estrategia de reforma inspirada en la NGP. Pero incluso sin que se produzca un cambo de propiedad, la NGP extiende claramente las prácticas de mercado a todos los ámbitos del sector público, incluyendo los SeIG que todavía se proveen públicamente. Dados los cambios fundamentales que implica la NGP y la privatización, no sorprende que haya emergido un enfoque teórico que se opone frontalmente al enfoque «desde la demanda».

\section{El enfoque «basado en el derecho» a los SelG}

De acuerdo con este enfoque, los ciudadanos tienen determinados derechos en relación con los proveedores de servicios considerados «de interés general»: acceso a precios transparentes y asequibles, un servicio prestado de manera continuada, etc. Así, el enfoque «basado en el derecho» conceptualiza la relación entre usuarios y proveedores como una relación jurídica que debe garantizar ciertas cualidades de la prestación de servicios. En definitiva, los parámetros de calidad de los SeIG deben quedar definidos políticamente, lo que indica el fuerte carácter normativo de este enfoque.

¿Cómo puede garantizarse la aplicación de estos derechos políticos? La forma más fácil y efectiva, de acuerdo con este enfoque, es mantener los SeIG en la propiedad pública, porque los proveedores públicos de servicios son directamente responsables ante las instituciones políticas que definen y garantizan los derechos al disfrute de los SeIG. De forma alternativa, cuando no sea posible o viable la prestación de SeIG por parte de proveedores públicos, puede acudirse a proveedores privados que operan sobre la base de estrictas obligaciones públicas y están estrechamente controlados por organismos públicos reguladores.

El enfoque «basado en el derecho» a la prestación de SeIG conduce a cuestiones de política más amplias ya que debe garantizar la igualdad de derechos de todos los ciudadanos en cuanto a la prestación de SeIG. Lograr la igualdad significa realizar importantes esfuerzos adicionales para mejorar las condiciones de prestación y acceso a SeIG para los ciudadanos cuyas circunstancias están muy por debajo del promedio. Y si los SeIG son, de hecho, de vital importancia para la calidad de vida y el desarrollo económico, la igualdad en la prestación de SeIG forma parte de una estrategia más amplia de garantizar la igualdad de condi- 
ciones de vida para todos los ciudadanos. Así, el enfoque «basado en el derecho» a los SeIG entronca con el objetivo de cohesión social y territorial presente en todas las estrategias y un buen número de políticas de la UE.

\section{Cohesión territorial y SelG}

El debate anterior también puede afrontarse desde una perspectiva territorial. Desde este punto de vista, los principales objetos de análisis cambian de ciudadanos y grupos sociales a localidades y regiones. Por ejemplo, puede analizarse la dotación de SeIG de una región (servicios que están presentes, su calidad, otros servicios accesibles en regiones adyacentes en tiempo razonable, etc.). Estas características pueden compararse entre regiones. Cuanto mayor sea la diferencia entre regiones, menor será la cohesión territorial en lo que respecta a los SeIG. Por supuesto, hay también otros aspectos que componen el concepto de «cohesión territorial», pero los SeIG desempeñan un papel clave: por definición, los SeIG se consideran esenciales para el bienestar de los habitantes y para el desarrollo económico de las empresas de una región. La cuestión que se plantea, sin embargo, es si los SeIG conllevan un aumento o disminución de la cohesión territorial entre las regiones. Se examinan a continuación dos «teorías fundamentales» del desarrollo regional con el fin de analizar esta cuestión.

La teoría neoclásica del desarrollo regional afirma que dentro de una economía de libre mercado los desequilibrios económicos entre regiones disminuyen y, finalmente, desaparecen. Esta afirmación se basa en el supuesto de libre circulación de trabajadores (movilidad laboral) y libre circulación de mercancías (libre comercio). Por lo tanto, los trabajadores que viven en una región pobre con un nivel salarial bajo pueden desplazarse a una región más rica en la que pueden obtener salarios más altos. Pero esto crea una escasez relativa de trabajadores en la primera región lo que incrementa el nivel de los salarios. Por otra parte, la afluencia de trabajadores a la segunda región crea una abundancia relativa de trabajadores que puede conducir a una disminución del nivel salarial. A través de muchos mecanismos como este, y otros más complejos, las economías de ambas regiones alcanzarán una situación de equilibrio: un caso de cohesión territorial perfecta.

¿Cómo se comportan los SeIG en el marco de la teoría regional neoclásica? En primer lugar, ciertos SeIG -como las infraestructuras y servicios de transporte y telecomunicacionesson cruciales para el funcionamiento de esta teoría, ya que se basan en el «libre» (idealmente instantáneo y sin costos) movimiento de personas, bienes e información. Estos SeIG deben ser operados por empresas privadas de modo que su oferta y demanda quedará ajustada constantemente por los mecanismos de mercado. En realidad, de acuerdo con sus fundamentos teóricos e ideológicos, la teoría neoclásica del desarrollo plantea que debe existir el libre mercado, es decir, sin intervención del Estado, para todos los bienes y servicios.

La Teoría de la Polarización se ocupa específicamente de las diferencias entre áreas metropolitanas y áreas rurales. Un área metropolitana se caracteriza como un centro de innovación y crecimiento económico. Debido a sus mejores condiciones para el crecimiento, las metrópolis atraen capital financiero, recursos naturales y mano de obra desde sus áreas de influencia rurales que, de este modo, se ven drenadas en cuanto a sus principales recursos productivos. Como consecuencia, se incrementan los desequilibrios entre unas metrópolis en expansión y una periferia rural en declive. Sin embargo, también se produce un pro- 
ceso compensatorio mediante el que los efectos positivos del crecimiento metropolitano se extienden a las zonas rurales, por ejemplo, a través del turismo de fin de semana o de una mayor demanda de alimentos para la creciente población urbana. El rápido crecimiento de las metrópolis también da lugar a efectos adversos como la congestión, la contaminación, o el incremento del precio de la vivienda o del suelo para actividades productivas, etc. Estos procesos inducen a algunas empresas y familias a salir de la metrópoli. Por lo tanto, con el tiempo, el proceso de polarización entre el centro y la periferia se invertiría y comenzarían a prosperar sub-centros ubicados en las zonas rurales. Al final existiría un sistema estable y diferenciado de asentamientos que irían desde pequeñas aldeas, pueblos rurales y centros suburbanos hasta la metrópolis central. En resumen, después de un prolongado período de creciente polarización del sistema territorial finalmente se alcanzaría a una situación de mayor (aunque no perfecta) cohesión territorial.

En resumen, la teoría de la polarización describe procesos de desarrollo temporal y espacial bajo condiciones de economía libre de mercado. A pesar de que actúan procesos contradictorios, la teoría predice un vaciamiento de las zonas rurales durante la primera etapa y un crecimiento rural como consecuencia del desbordamiento de la metrópoli en una fase posterior del desarrollo. Algunos teóricos incluso dudan de que la segunda etapa ocurra necesariamente. En cualquier caso, las implicaciones para la toma de decisiones irían por el camino de contrarrestar la polarización o promover una inversión inicial del proceso y, de esa forma, lograr la cohesión territorial entre las zonas urbanas y rurales. Los SeIG podrían desempeñar un papel importante en esa política de cohesión territorial, ya que conforma la ventaja de localización de las zonas urbanas y rurales en las decisiones de localización residencial y económica.

\section{Teoría de la Localización y SeIG}

Los SeIG, especialmente los servicios de transporte, desempeñan un papel clave en las teorías de la localización. Básicamente, estas teorías tratan de explicar las decisiones de localización de individuos y agentes económicos. Harold Hotelling (1931) proporciona una explicación económica sencilla a través del «principio de la diferenciación mínima» que expone por qué servicios similares que atienden directamente un segmento de la sociedad se agrupan con el fin de capturar la mayor área de mercado posible. Por supuesto, también existen desventajas para una empresa que se ubica junto a sus competidores. A veces tiene sentido que una empresa trate de incrementar su diferenciación en cuanto a ubicación con respecto a otras empresas, en vez de minimizarla, como propone Hotelling.

Encontramos un referente teórico más complejo en la obra de Alfred Weber (1909). Su teoría de la localización industrial explica el surgimiento de las aglomeraciones desde el punto de vista económico. Weber demostró por primera vez cómo la ubicación de instalaciones productivas está determinada por la ubicación de sus proveedores y clientes, y por los costes de transporte respectivos. Dichos costes también definen el área geográfica de un mercado de trabajo asociado a un entorno productivo, dado que los trabajadores tienen un presupuesto fijo y limitado para desplazarse de su lugar de residencia al trabajo, y viceversa. Por tanto, la disponibilidad, precios y rutas de la infraestructura y servicios de transporte constituyen factores clave de las decisiones de localización individuales. Por otra parte, el 
área geográfica en la que se superponen diversas áreas de influencia de mercados de trabajo se convierte en el lugar preferido de localización, ya que permite el empleo en cualquiera de las empresas de las distintas áreas de mercado de trabajo sin tener que mover la residencia. Así, debería producirse una concentración poblacional en estas áreas de solapamiento que supondrían el germen de una aglomeración. Como consecuencia, todas las nuevas empresas decidirían instalarse en esta aglomeración para localizarse cerca de la mayor cantidad posible de clientes y atraer trabajadores a bajo coste. Este proceso sería de aplicación no solo a empresas industriales sino, incluso en mayor medida, a empresas de servicios para las que una buena accesibilidad a los clientes es incluso más importante. Por lo tanto, los servicios se concentrarán generalmente en lugares cercanos a la residencia de la mayoría de sus clientes.

Una segunda teoría clásica de localización fue desarrollada por Walter Christaller (1933). Su teoría del Lugar Central trató de ofrecer una explicación general para el tamaño, número y distribución de las ciudades. El punto de partida de esta teoría fue la constatación de que los distintos bienes y servicios tienen áreas de captación de diferente tamaño. Por ejemplo, los clientes de una panadería sólo aceptarían un desplazamiento corto para su compra diaria de pan, mientras que los clientes de una joyería estarán dispuestos a viajar una distancia mucho mayor para una adquisición que se produce, pongamos, una vez al año. Por tanto, en una ciudad habría un número indeterminado de panaderías con áreas de influencia pequeñas, mientras que podría haber una sola joyería, situada en un lugar central, que abasteciera a todos los ciudadanos. Sobre esta base, Christaller desarrolla un sistema jerárquico de localizaciones con diferentes grados de centralidad, cada uno de los cuales tendría diferentes comercios y servicios de conformidad con su centralidad.

La teoría del Lugar Central se presta muy bien a un análisis de localización de los SeIG. Se puede diferenciar SeIG con mayor frecuencia de utilización (por ejemplo, una farmacia o un consultorio médico) o con menor frecuencia (por ejemplo un hospital), y determinar si la ubicación actual es la más adecuada dentro del sistema del lugar central. De manera similar, puede identificarse la localización óptima para un nuevo servicio. Esta es la razón por la que la teoría del Lugar Central se está utilizando en muchos países para determinar la ubicación de los servicios públicos o para la definición de las ciudades que deben poseer determinados servicios públicos (a este respecto, véase también la sección siguiente).

\section{ANÁLISIS EMPÍRICO EN RELACIÓN CON LOS SEIG}

En esta sección del artículo se revisa la escasa evidencia empírica existente sobre la evolución, situación y mecanismos de cambio subyacentes en los SeIG en Europa. Se procede, en primer lugar, a la presentación de la evidencia cuantitativa a través de un conjunto de pruebas y análisis que proporcionan el telón de fondo general para el análisis cualitativo posterior.

\section{Evidencia cuantitativa sobre los SelG en Europa}

La historia de los SeIG en Europa es larga, y ha sufrido muchos cambios. Sin embargo, las últimas tres décadas han sido particularmente agitadas, en parte debido a las innovacio- 
nes tecnológicas (por ejemplo, la telefonía móvil o Internet), y también debido a los cambios radicales registrados en la política en materia de SeIG. Entre estos cambios, destacan los sucedidos en las políticas nacionales (a menudo como consecuencia de orientaciones o directrices europeas y de otros organismos internacionales como la OCDE o el FMI) para privatizar algunos de los servicios públicos tradicionales.

\subsection{La privatización de SelG}

Los servicios públicos han jugado un papel importante en la evolución histórica de los Estados europeos. Especialmente desde la revolución industrial y después de la Segunda Guerra Mundial, los servicios públicos se expandieron en todos los países europeos y se convirtieron en uno de los pilares del modelo europeo del Estado del Bienestar. A pesar de que hubo una fuerte resistencia interna a permitir que las fuerzas del mercado se hiciesen cargo de la provisión de servicios públicos, a partir de la década de 1980 las políticas de la UE y nacionales han abogado por la privatización de servicios públicos a gran escala (Figura 2).

Figura 2

PROCESOS DE PRIVATIZACIÓN EN LA UE, 1981-2002 (EN MILLONES DE \$)

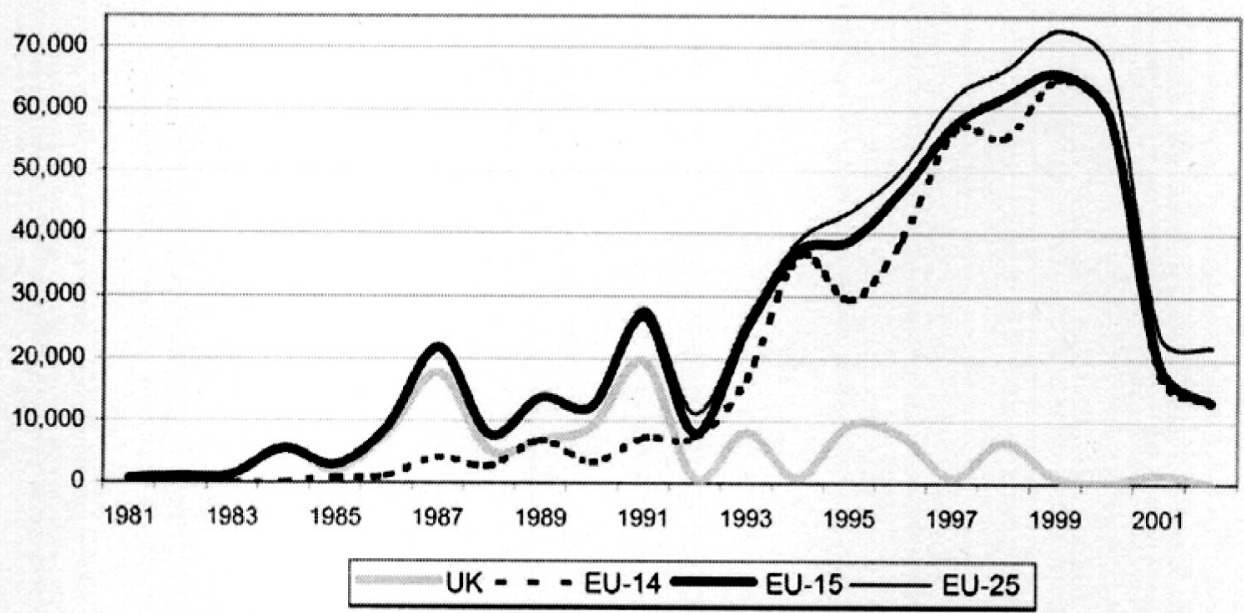

Fuente: Clifton et al. (2006). Basado en 742 Privatization Barometer (2005).

La Figura 2 muestra la distribución temporal de los procesos de privatización en la Unión Europea. Si se compara la línea de la UE14 con la del Reino Unido se ve claramente que, durante toda la década de 1980, apenas hubo privatizaciones fuera del Reino Unido, donde Margaret Thatcher hacía evidente el efecto de sus políticas de libre mercado. Sin embargo, a partir de 1993, la mayoría de países europeos siguieron el ejemplo británico y se embarcaron en ambiciosas políticas de privatización. Los ingresos por procesos de privatización alcanzaron su punto máximo en 1999 con 66.000 millones de US\$ (Privatisation Barometer, 2005). Hay que tener en cuenta, en todo caso, que esta cifra también incluye los ingresos derivados 
de la privatización de las empresas industriales estatales o de participaciones públicas en empresas industriales.

La privatización de SeIG ha seguido patrones similares, con algunas diferencias sectoriales. En el sector de transporte, por ejemplo, la privatización normalmente se centró en las líneas aéreas nacionales, mientras que el transporte ferroviario continúa, en gran parte, en manos del sector público en la mayoría de países europeos. La Figura 3 muestra los ingresos por privatizaciones en el sector de las telecomunicaciones y abastecimiento. De nuevo se observa la función pionera del Reino Unido en los procesos de privatización. Los demás países europeos sólo empezaron una tendencia consolidada a la privatización de sus empresas de telecomunicaciones a partir de 1994. Sin embargo, las elevadas cifras de los 90 no debe ocultar el hecho de que, en varios países, la propiedad estatal seguía siendo fuerte o incluso dominante en el sector de las telecomunicaciones. En el ámbito del abastecimiento (gas, electricidad y agua) la mayoría de las transacciones de privatización se produjeron en 1998 y 1999, cuando los mercados de valores eran fuertes. Sin embargo, sigue siendo la norma la propiedad pública o mixta de las empresas de servicios públicos, con las excepciones parciales de Francia y España en lo que respecta a la provisión de agua (Clifton, 2006).

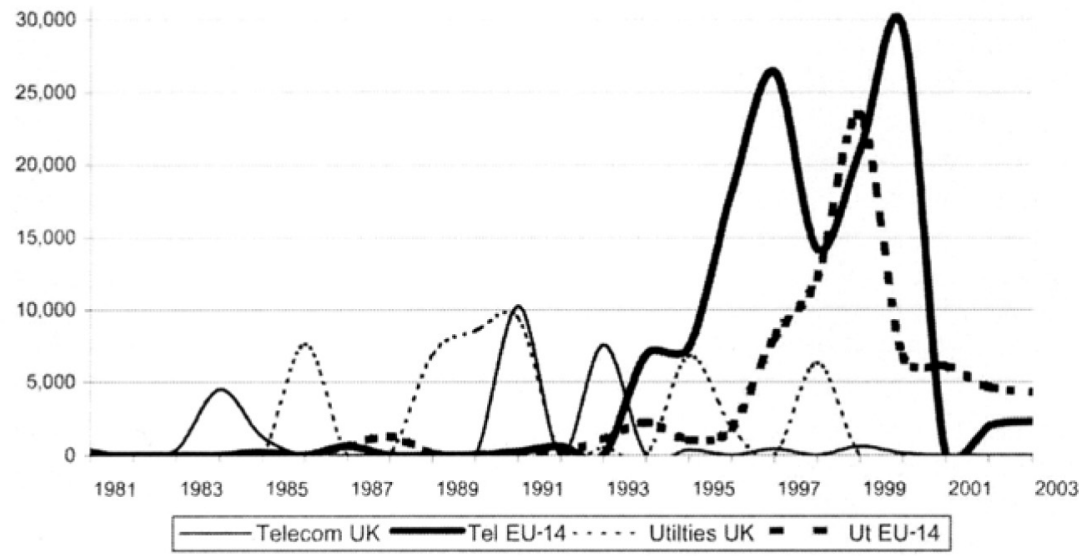

Fuente: Clifton et al. (2006). Basado en 742 Privatization Barometer (2005).

Por supuesto, estas cifras de privatización sólo ofrecen una imagen parcial de los cambios acontecidos en los sectores respectivos. En paralelo, o con anterioridad a la privatización de empresas estatales, se liberalizaron los mercados sectoriales correspondientes, lo que permitió a los proveedores de servicios privados entrar a competir con el anterior monopolio del Estado. Así, si se comparasen los ingresos reales de las empresas estatales, a menudo se haría evidente una descapitalización dramática. Puede que los principales servicios no estén completamente privatizados (todavía), pero la cuota de mercado de los proveedores públicos se ha reducido considerablemente. 


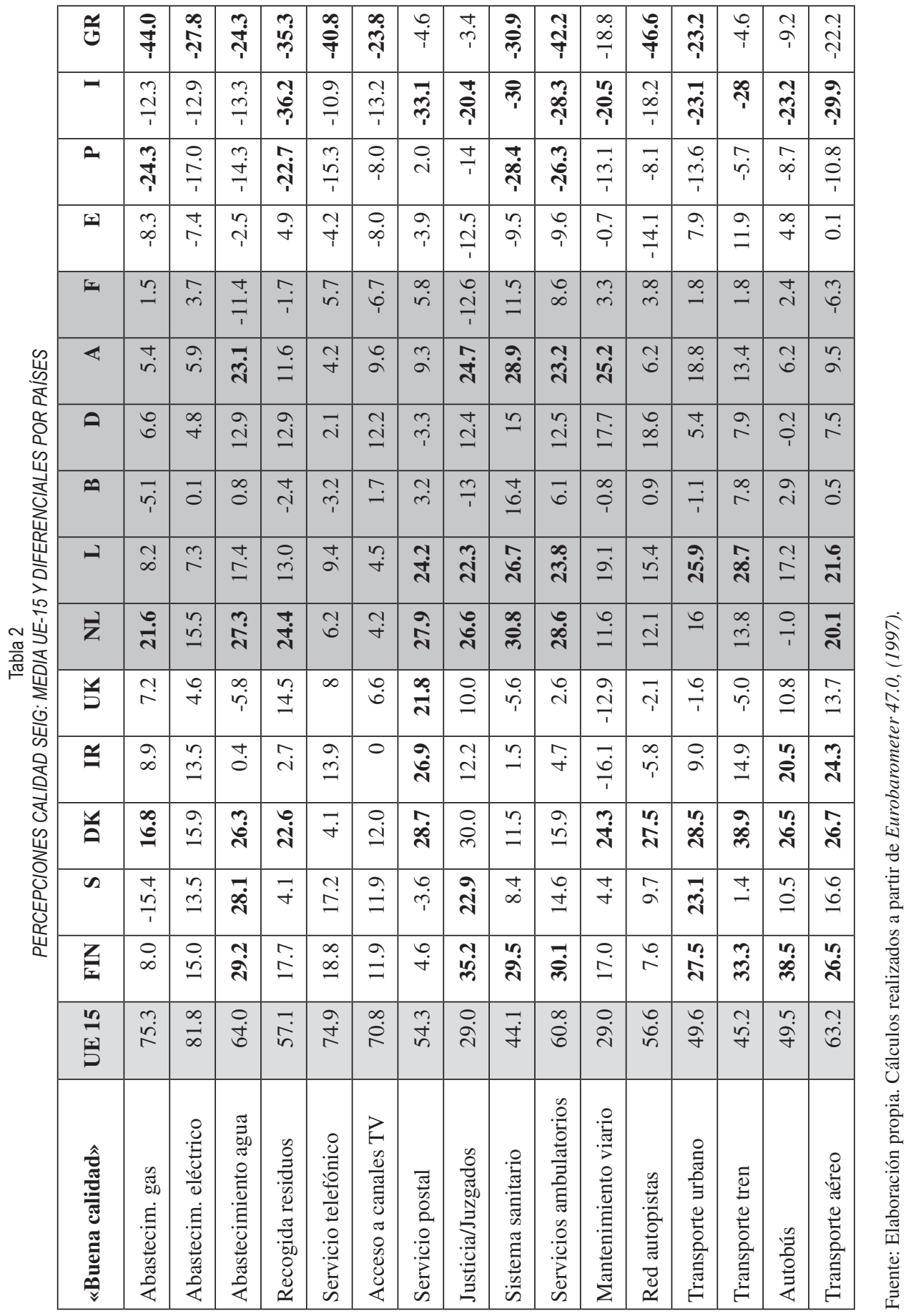




\subsection{Calidad/accesibilidad a SelG (1997)}

La Tabla 2 presenta una instantánea de la situación de los SeIG en Europa en 1997, a partir del Eurobarómetro 47.0. Se preguntó a los ciudadanos sobre la calidad de una serie de servicios que van desde las infraestructuras técnicas, servicios de comunicación, justicia y servicios de salud, a los servicios de transporte. A diferencia de Eurobarómetros posteriores que preguntaban acerca del acceso, uso, calidad, etc., por separado, éste sólo preguntó sobre la calidad de estos servicios. Por tanto, es presumible que los entrevistados incluyesen en sus valoraciones todo tipo de aspectos que se reflejan en la calidad de los servicios, por ejemplo, la forma de acceso o el costo de la prestación, si el servicio es ininterrumpido, si las relaciones con los clientes son satisfactorias, si el servicio ofrece «una buena relación calidad-precio», etc.

La primera columna muestra el promedio de la UE-15 para cada servicio, las siguientes columnas indican, para cada país, el número de puntos porcentuales que su promedio nacional difiere de la media europea. Los valores en negrita son los que marcan los diferenciales mayores del $20 \%$ por encima o por debajo de la media de la UE-15.

Para un análisis sectorial en bruto pueden observarse los promedios europeos. Los dos primeros «sectores» de los servicios (infraestructura técnica y servicios de comunicación) obtienen puntuaciones relativamente altas, que van desde más de $50 \%$ a casi el $82 \%$. En el siguiente grupo, los servicios ambulatorios de salud también obtienen un alto porcentaje, pero el sistema de salud como tal (hospitales, etc.) tiene menos de 50 por ciento de aprobación. Esta puntuación sólo es superada a la baja por el sistema de justicia para el que menos de un tercio de los encuestados opina que ofrece una «buena calidad». El último grupo de servicios gira en torno a los transportes. La mayoría de estos servicios tiene índices de aprobación entre el $45 \%$ y el $63 \%$. Sólo el estado de las carreteras (mantenimiento) obtiene una puntuación muy baja (29\%).

Un análisis comparativo de los resultados entre países da una visión más diferenciada. Podemos concluir que los ciudadanos de la mayoría de los países de Europa del Norte y Central otorgan calificaciones de calidad muy por encima de la media europea. En este sentido, los únicos resultados sorprendentes son las bajas puntuaciones otorgadas al suministro de gas en Suecia, al mantenimiento de carreteras en Irlanda y el Reino Unido, al sistema de justicia en Bélgica y Francia, y al suministro de agua en Francia. Los países con, al menos, cinco servicios que obtienen calificaciones de calidad más del $20 \%$ de la media europea son Finlandia, Dinamarca, Países Bajos, Luxemburgo y Austria. En contraste, los ciudadanos de los países europeos meridionales otorgan calificaciones de calidad por debajo de la media europea. España se sitúa, para la mayoría de los SeIG, en puntuaciones que no superan el $10 \%$ por debajo de la media europea, pero Portugal, Italia y Grecia se encuentran en muchas áreas muy significativamente por debajo de los estándares europeos. De hecho, Grecia sólo cuenta con tres servicios que no obtienen calificaciones por debajo de $-20 \%$ de la media europea.

En resumen, las percepciones de los ciudadanos encuestados por el Eurobarómetro pueden sintetizarse de la siguiente manera: (a) los servicios técnicos, de comunicación y de transporte tienen buena calidad; (b) el sistema de justicia y de salud reciben calificaciones de muy baja calidad; (c) la calidad percibida en los países de Europa del Norte y Central es, en 
general, muy alta; (d) los países de la Europa meridional reciben calificaciones por debajo o muy por debajo de la calidad media de la UE.

Es necesario señalar, sin embargo, que estas calificaciones representan la calidad percibida de los servicios (evaluación subjetiva), que datan de 1997, y que se refieren a cada país en su conjunto, es decir, no diferencian entre zonas urbanas y rurales. En todo caso, el Eurobarómetro 47.0 constituye la primera encuesta paneuropea de recolección sistemática de datos sobre una amplia gama de SeIG.

\subsection{Calidad/accesibilidad a SeIG (2004)}

Una segunda y completa «instantánea» del estado de los SeIG de Europa se llevó a cabo en 2004, justo tras la incorporación de diez Nuevos Estados Miembros a la UE. El Eurobarómetro 62.1 y 62.2 incluye entre sus variables de perfil el lugar de residencia del encuestado. Con base en esta información, ha sido posible calcular los respectivos valores para las zonas rurales y urbanas. En la Tabla 3 se recogen estas diferencias en puntos porcentuales respecto de la media UE-25. La denominación de las respectivas categorías de respuesta de los servicios técnicos y los servicios sociales difieren un poco. Por ello, los cálculos que se muestran resumen los datos de todas las evaluaciones positivas de un servicio concreto (es decir, «acceso fácil « o «muy satisfecho»y «bastante satisfecho», respectivamente).

La Tabla 3 también resume los datos sobre la percepción de los encuestados en cuanto al acceso a los SeIG. Un primer análisis sectorial (primera columna) muestra elevados índices de calidad para el acceso a los servicios de comunicación, transporte y de abastecimiento (entre 68\% y 92\%). El acceso a los servicios de salud y educación también recibió altas puntuaciones, aunque algo menores que el grupo anterior (entre $63 \%$ y $76 \%$ ). La vivienda social tuvo la calificación más baja en cuanto a accesibilidad. Si nos centramos en las diferencias entre áreas rurales y urbanas (columnas 2 y 3), sorprende que para la mayoría de los servicios básicos (electricidad, servicios sociales), las áreas rurales muestran una mayor accesibilidad que las urbanas. Sin embargo, este dato esconde grandes diferencias entre la situación de las áreas rurales próximas a núcleos urbanos y la de las áreas rurales remotas y de montaña, donde una parte importante de estos servicios han desaparecido.

El análisis comparativo de la situación en los Nuevos Estados Miembros (NEM) frente a la «vieja Europa» (UE 15) revela grandes diferencias entre las respectivas áreas urbanas y rurales (columnas 4 a 7). Comparando primero las zonas rurales entre los 15 países de la UE y los NEM, resulta que el gas, la electricidad, los servicios postales, de telefonía móvil y servicios de cuidado infantil son más accesibles en las zonas rurales en los NEM. Por otra parte, la telefonía fija, servicios de ferrocarril, la vivienda social y los sistemas de salud son significativamente menos accesibles.

Al comparar las diferencias urbano-rurales entre la UE 15 y los NEM se llega a conclusiones interesantes: en la UE-15 las zonas urbanas generalmente tienen una puntuación más alta, pero en la mayoría de las zonas rurales los servicios sociales están por delante de las zonas urbanas. En los NEM esto sólo es cierto para la vivienda social y el sistema de salud. En general, si se calculan las diferencias urbano-rurales para todos los sectores, la diferencia global es negativa (las zonas rurales se están quedando atrás), pero esta diferencia es más del doble que para los NEM. 
Para concluir este análisis espacial general de acceso a SeIG, se puede decir que las diferencias entre las zonas urbanas y rurales, así como entre la UE-15 y los NEM son más complejas de lo esperado: (a) si bien en general es cierto que la percepción sobre el acceso a los SeIG es menor en las zonas rurales que en las zonas urbanas, (b) hay excepciones notables en el caso de algunos servicios sociales, que son más accesibles en las zonas rurales; (c) las zonas rurales de los NEM tienen a menudo SeIG más accesibles que las zonas rurales de la UE-15, (d), pero el acceso a los servicios ferroviarios, de telefonía fija, y la mayoría de los servicios sociales es comparativamente mejor en las zonas rurales de la UE.15; (e) las zonas urbanas en la UE-15 cuentan con servicios más accesibles en comparación con sus contrapartes rurales, (f), pero esto no es cierto para la mayoría de los servicios sociales que se perciben como más accesibles en las zonas rurales; (g) por último, las diferencias urbano-rurales son, en general, más de dos veces mayores en los NEM que en la UE-15.

Tabla 3

PERCEPCIONES SOBRE EL ACCESO A SEIG: MEDIA DE LA UE25 Y DIFERENCIALES

\begin{tabular}{|c|c|c|c|c|c|c|c|}
\hline & $\begin{array}{l}\text { Media } \\
\text { UE-25 }\end{array}$ & $\begin{array}{l}\text { Rural } \\
\text { UE-25 }\end{array}$ & $\begin{array}{c}\text { Urbano } \\
\text { UE-25 }\end{array}$ & $\begin{array}{l}\text { Rural } \\
\text { UE-15 }\end{array}$ & NEM & $\begin{array}{c}\text { Urbano } \\
\text { UE-15 }\end{array}$ & NEM \\
\hline \multicolumn{8}{|l|}{ «fácil acceso» } \\
\hline Abastecimiento agua & 92,5 & 0 & 0 & 0,1 & $-0,3$ & $-1,1$ & 5,7 \\
\hline Abastecimiento gas & 74,7 & $-8,1$ & 3,9 & $-11,0$ & 4,1 & 1,3 & 17,1 \\
\hline Abastecimiento electricidad & 92,3 & 0,9 & $-0,4$ & $-0,2$ & 5,5 & $-1,6$ & 6,0 \\
\hline Telefonía fija & 89,8 & $-0,2$ & 0,1 & 1,3 & $-7,2$ & 0,3 & $-0,9$ \\
\hline Telefonía móvil & 82,6 & -3.0 & 1,5 & $-3,3$ & $-1,6$ & 0,7 & 5,4 \\
\hline Servicio postal & 89,1 & $-1,8$ & 0,8 & $-2,3$ & 0,3 & $-0,4$ & 7,7 \\
\hline Servicio de tren interurbano & 68,2 & $-18,7$ & 9,1 & $-16,6$ & $-28,1$ & 8,6 & 12,3 \\
\hline Transporte urbano & 74,8 & $-17,1$ & 8,1 & $-17,4$ & $-15,7$ & 7,2 & 12,7 \\
\hline \multicolumn{8}{|c|}{ «muy+bastante satisfecho con condiciones acceso» } \\
\hline Vivienda social & 49,7 & $-0,4$ & 0,2 & 1,8 & $-13,0$ & 3,4 & $-20,0$ \\
\hline Sistema educativo & 76,5 & 0,6 & $-0,4$ & 0,7 & 0,6 & $-1,1$ & 3,5 \\
\hline Formación complementaria & 70,1 & 1,3 & $-0,6$ & 1,7 & $-1,2$ & $-1,9$ & 5,9 \\
\hline Sistema sanitario & 67,1 & 2,2 & $-1,3$ & 4,3 & $-7,2$ & 2,1 & $-19,2$ \\
\hline Guardería infantil & 63.0 & $-0,1$ & 0 & $-0,3$ & 0,8 & $-2,5$ & 13,7 \\
\hline
\end{tabular}

Fuente: Elaboración propia a partir de Eurobarometer 62.1 and 62.2, (2004). 


\subsection{Calidad de los SelG}

La Tabla 4 resume los datos sobre calidad percibida de los SeIG en Europa. A nivel metodológico, debe tenerse en cuenta que la pregunta sobre calidad del servicio sólo se realizó a los encuestados del Eurobarómetro 62 que indicaron que tienen acceso y utilizan realmente los servicios respectivos. Así, los datos son muy diferentes de los que se muestran en la Tabla 2, que refleja los resultados de todos los ciudadanos encuestados, y probablemente también incluye la insatisfacción debido a la falta de disponibilidad de un servicio, baja accesibilidad, etc. Por el contrario, La Tabla 4 muestra sólo los resultados de los usuarios del servicio.

A nivel agregado de la UE-25 (primera columna) la percepción sobre la calidad de los servicios públicos es, mayoritariamente, «buena» o «muy buena». La comparación de la calidad de los SeIG en áreas urbanas y rurales muestra niveles de calidad más elevados en las áreas rurales con la única excepción de la telefonía móvil. Si avanzamos en el análisis entre áreas urbanas y rurales, y UE-15 y NEM, aparecen patrones más complejos. Las áreas rurales de la UE-15 muestran mejor calidad que la media en 7 servicios, mientras que las áreas rura-

Tabla 4

PERCEPCIONES SOBRE CALIDAD DE LOS SEIG: MEDIA DE LA UE-25 Y DIFERENCIALES

\begin{tabular}{|c|c|c|c|c|c|c|c|}
\hline & $\begin{array}{l}\text { Media } \\
\text { UE-25 }\end{array}$ & $\begin{array}{l}\text { Rural } \\
\text { UE-25 }\end{array}$ & $\begin{array}{c}\text { Urbano } \\
\text { UE-25 }\end{array}$ & $\begin{array}{l}\text { Rural } \\
\text { UE-15 }\end{array}$ & NEM & $\begin{array}{c}\text { Urbano } \\
\text { UE-15 }\end{array}$ & NEM \\
\hline \multicolumn{8}{|c|}{ «calidad muy buena o buena» } \\
\hline Abastecimiento agua & 94.3 & 0.5 & -0.3 & 0,8 & $-0,8$ & 0,1 & $-2,7$ \\
\hline Abastecimiento gas & 95.4 & 0.7 & -0.3 & 1,6 & $-1,7$ & $-0,4$ & $-0,1$ \\
\hline Abastecimiento eléctrico & 95.4 & 0 & 0 & $-0,2$ & 0,4 & $-0,3$ & 1,1 \\
\hline Telefonía fija & 92.9 & 0.5 & -0.3 & 0,7 & $-0,8$ & $-0,1$ & $-1,6$ \\
\hline Telefonía móvil & 92.1 & -1.0 & 0.4 & $-1,8$ & 2,9 & $-0,4$ & 4,7 \\
\hline Servicio postal & 86.7 & 2.4 & -1.1 & 1,2 & 7,0 & $-2,2$ & 3,9 \\
\hline Servicio ferrov. Interurbano & 76.0 & 1.8 & -0.6 & 1,3 & 4,7 & 0,4 & $-5,0$ \\
\hline Transporte urbano & 79.7 & -0.1 & 0 & $-0,6$ & 1,4 & $-0,2$ & 0,6 \\
\hline \multicolumn{8}{|c|}{ «muy satisfecho y bastante satisfecho con calidad» } \\
\hline Vivienda social & 56.4 & 0,8 & $-0,3$ & 3,2 & $-14,1$ & 2,6 & $-19,3$ \\
\hline Sistema educativo & 65.7 & 1,3 & $-0,6$ & $-0,2$ & 8,9 & $-1,6$ & 4,4 \\
\hline Formación complementaria & 70.0 & 3,3 & $-1,8$ & 3,5 & 2,5 & $-2,9$ & 4,2 \\
\hline Sistema sanitario & 61.6 & 4.0 & $-2,1$ & 7,2 & $-10,7$ & 1,7 & $-22,2$ \\
\hline Guardería infantil & 71.8 & 2,5 & $-1,3$ & 2,7 & 1,3 & $-2,8$ & 7,4 \\
\hline
\end{tabular}

Fuente: Elaboración propia a partir del Eurobarometer 62.1 and 62.2, (2004). 
les de los NEM muestran mejor calidad en 5 servicios. Los principales déficits en este caso están en los servicios sociales.

En conclusión, de acuerdo con la opinión de sus usuarios, (a) las áreas rurales muestran niveles de calidad de los SeIG superiores a las áreas urbanas; (b) los diferenciales entre áreas urbanas y rurales son significativamente mayores en los NEM.

La comparación entre la valoración del acceso a, y calidad de, los SeIG, permite hacer las siguientes valoraciones: en primer lugar, en general, los encuestados del Eurobarómetro 62 expresan una satisfacción relativamente alta con la calidad del servicio y el acceso a los SeIG; en segundo lugar, los servicios sociales registran percepciones menos satisfactorias que los servicios de abastecimiento, comunicación y transporte, tanto en lo que respecta a acceso como a calidad; en tercer lugar, los residentes de las zonas urbanas parecen tener un mejor acceso a los SeIG, aunque la calidad es mejor en las zonas rurales; en cuarto lugar, las diferencias entre zonas urbanas y rurales son más elevadas en los NEM que en los países de la UE 15; en quinto lugar, las zonas rurales de los países del norte y centro europeos tienen niveles de acceso y de calidad de SeIG significativamente más altos, especialmente para los servicios sociales; en sexto lugar, las zonas rurales de los países del sur presentan puntuaciones más bajas en lo que respecta a la calidad del servicio, y puntuaciones mucho más bajas para el acceso, especialmente a los servicios sociales; por último, las zonas rurales de los países de Europa del Este tienen calificaciones muy heterogéneas en accesibilidad y calidad de los servicios. Algunos países muestran puntuaciones muy favorables, mientras la mayoría muestran importantes déficits en materia de acceso a los servicios. La calidad del servicio es, en general, mejor, pero también presenta deficiencias.

\section{Análisis cualitativo del desarrollo de los SelG en Europa}

Se analizan a continuación los mecanismos causales que explican los procesos de cambio en los SeIG en Europa. Después de una revisión introductoria se procede a una breve revisión histórica de la evolución de los SeIG en los espacios rurales europeos. A continuación se realiza una comparación de diferentes experiencias nacionales, regionales y locales en provisión de SeIG.

\subsection{Accesibilidad a SelG y áreas rurales: condiciones generales y procesos de cambio}

En el contexto de un mundo rural extenso y diverso, donde en la mayoría de los casos, la actividad humana es menos intensa y el tamaño de los asentamientos más reducido, se plantean más y mayores limitaciones a la accesibilidad, sobre todo para los grupos sociales más desfavorecidos (Moseley, 2000). El acceso y uso de los SeIG, casi siempre lejos de los estándares de calidad urbanos, implica un esfuerzo mayor en coste económico, tiempo y consumo de energía, tanto para los residentes rurales como para las organizaciones públicas y privadas responsables de su provisión y mantenimiento.

El impacto de las dificultades descritas se agrava debido a la reducida dimensión de los mercados locales en las zonas rurales y a la aparente escasez en la prestación de servicios. Labasse (1973) ya hizo mención de este problema al afirmar que «cualquier equipamiento colectivo se concibe de acuerdo con la cuestión de la centralidad» (ibid.;551), y que los 
contrastes entre los asentamientos urbanos y rurales debían hacer pensar en las necesidades y limitaciones de la movilidad de los campesinos.

En las zonas rurales más remotas, la despoblación, junto a la contracción de los mercados de trabajo locales, pueden conducir al aumento de las disparidades intra e inter-regionales. La pérdida progresiva de la competitividad de las economías rurales, que, en muchos casos, no pueden hacer frente a los desafíos de la globalización económica, es una de las principales preocupaciones de la UE que dedica una parte sustancial y creciente de su política regional (y, más recientemente, también la política agraria) a promover el desarrollo rural y el aumento de la competitividad de las zonas rurales (Comisión de las Comunidades Europeas de 1994, 2004b, 2007).

En estas áreas, los problemas relacionados con la accesibilidad constituyen un grave obstáculo para el desarrollo o para la satisfacción de las necesidades y expectativas personales y grupales. La pérdida continuada de población acaecida en muchas zonas rurales durante las últimas décadas es causa y consecuencia, al mismo tiempo, de la reducción de la prestación y accesibilidad a los SeIG. Esto, a su vez, reduce las posibilidades de aumentar la base poblacional. Esta secuencia forma la base de la llamada «naturaleza cíclica del declive rural» (Gilg,1983) con múltiples consecuencias en las vidas de los residentes rurales, como la reducción de las posibilidades de obtener un empleo adecuado o para involucrarse en actividades sociales (Storey y Brannen, 2000), o el mayor riesgo de exclusión social y aislamiento personal (Rostami, 2005).

La disminución en la prestación de servicios y la consiguiente reducción de las condiciones de accesibilidad para muchos SeIG en las zonas rurales tienen, sin duda, un impacto negativo sobre las posibilidades de mantener un tejido social vivo y dinámico. Por lo tanto, la situación, la disponibilidad y las perspectivas de la prestación de servicios en las zonas rurales es uno de los principales impulsores del cambio para lograr un desarrollo sostenible a largo plazo, y para contribuir a reducir las disparidades regionales.

\subsection{Comparativa internacional: la relevancia de los contextos territoriales}

El análisis empírico de la accesibilidad a SeIG en zonas rurales de la UE muestra consideraciones y tratamientos heterogéneos del tema de acuerdo con las fuentes de referencia. Por un lado, existe abundante literatura sobre la demanda, disponibilidad y acceso a SeIG en las áreas rurales de países de Europa occidental, principalmente del Reino Unido y Escandinavia. Esta parte de la literatura pone de relieve cuestiones como las diferentes culturas de movilidad en las zonas rurales y sus consecuencias sobre la accesibilidad y prestación de servicios, o la cuestión de la «equivalencia territorial». Es también el contexto en el que se describen por primera vez formas innovadoras de prestación de servicios en las áreas donde los umbrales de población no permiten su conservación en virtud de las fórmulas tradicionales.

En el caso de los países mediterráneos, la mayoría de los análisis y estudios de caso se refiere a la problemática asociada a la despoblación de las zonas rurales remotas y desfavorecidas. La despoblación intensa de la montaña mediterránea ha causado procesos similares en todos los países mediterráneos (Portugal, España, sur de Francia, Italia y Grecia). En la mayoría de las zonas rurales remotas y de montaña de estos países, el proceso cumulativo de pérdida de las funciones económicas tradicionales, y la consecuente emigración, han tenido 
como consecuencia un intenso despoblamiento. El porcentaje de pérdida de población en relación a 1950 es del 50\% o más en la mayoría de los casos. La consecuencia lógica de este proceso de vaciado es que muchos de los asentamientos rurales más pequeños se han convertido en inviables en cuanto a su capacidad para mantener su población restante. Muchos otros pueblos y ciudades, a pesar de estar todavía habitados, registran una importante reducción en los niveles de prestación y calidad de SeIG. Hay una reducción general en la calidad de vida y el bienestar de la población rural causados por la despoblación y sus consecuencias.

En relación con la prestación y el acceso a los SeIG, estos procesos se traducen en un incremento del tiempo de acceso a los servicios disponibles, la falta de prestación de servicios en muchos pueblos y ciudades debido a la inviabilidad económica, las limitaciones económicas de la población demandante, y la falta de políticas y programas adecuados para contrarrestar el cierre progresivo de los SeIG en las zonas más aisladas y desfavorecidas. Por otra parte, durante las últimas dos décadas, la montaña mediterránea se ha convertido en el lugar de asentamiento (permanente o estacional) de nuevos colectivos (migración de retorno, vacaciones estivales, retiro de jubilados del centro y norte de Europa, flujos inmigratorios desde diferentes regiones del mundo, etc.). Los «recién llegados» son esenciales para la revitalización de las zonas rurales más remotas y montañosas, pero también suponen un importante reto para integrar a los consumidores nuevos y a sus comportamientos de movilidad. Por ejemplo; Auyda et al. (2002), señalan como una posible solución la concentración funcional y territorial de los servicios en un número reducido de localizaciones seleccionadas de acuerdo con su relevancia geográfica o poblacional, y el establecimiento de redes flexibles de provisión de servicios. Este proceso se hace más evidente en las zonas rurales remotas y montañosas, donde la estructura urbana es débil y va en detrimento de las demandas de los asentamientos más pequeños en relación a la mejora de las condiciones actuales de accesibilidad a los servicios. Se reconoce, implícitamente, la falta de viabilidad económica de dichos lugares y la dificultad de que sus habitantes un día gocen del derecho a la igualdad de acceso.

Por el contrario, todavía en el ámbito de los países mediterráneos, apenas se encuentran referencias a la situación de la oferta y el acceso a los SeIG en las zonas rurales accesibles, que están recibiendo, en gran medida, las consecuencias del rápido crecimiento urbano como resultado de la reubicación de actividades productivas y residenciales de las ciudades cercanas. Por otra parte, esto sucede en regiones en las que se están produciendo cambios rápidos en la configuración territorial tradicional, no siempre guiados por una planificación adecuada, lo que amenaza la racionalidad del modelo territorial resultante. Además, una vez más, la llegada de «nuevos pobladores» al medio rural plantea el reto de cómo combinar las diferentes culturas de demanda y acceso a servicios que ahora confluyen en estos territorios.

\subsection{Estudios locales y regionales}

En el ámbito de la ordenación del territorio y, dentro de ella, de la planificación de la prestación y acceso a los SeIG, los primeros estudios se realizaron en el Reino Unido en la década de 1980 con el fin de caracterizar las necesidades de las comunidades locales en relación con el transporte público, teniendo en cuenta variables demográficas, de disponibilidad de vehículo privado y la oferta de transporte público disponible (Parolin, 1984; Bird,1987). 
Otros estudios se refieren a la propuesta e implementación de soluciones innovadoras para la prestación y el acceso a estos servicios en las zonas rurales. Por ejemplo, hay un caso llevado a cabo en Yorkshire (Reino Unido), el «South Pennines Rail Partnership (SPRP)», donde las empresas privadas y las instituciones públicas se han asociado con el fin de promover el turismo sostenible a través de la promoción de viajes por ferrocarril, la creación de estaciones de interconexión en las zonas de baja accesibilidad, la reducción de la exclusión social, y el incremento de la concienciación para el uso de un transporte respetuoso con el medio ambiente. Esta experiencia ha tenido efectos muy positivos, como el fortalecimiento de los actores locales y regionales, así como una mayor consolidación de sus redes, lo que ha contribuido a asegurar la financiación y la viabilidad de los proyectos presentes y futuros (Commission for Rural Communities, 2008).

Power y Shaw (2004) estudiaron las funciones futuras de los asentamientos rurales como centros de servicio para las áreas de interior de la región de Alnwick (noreste de Inglaterra) a través de un programa denominado «Market Town Initiative» enel que participaron 13 asentamientos rurales. Se analizaron los «servicios de acceso autónomo» en los que el residente o cliente tiene que desplazarse por sus medios (por ejemplo, la atención sanitaria y los servicios al por menor). Llegaron a la conclusión que los principales factores para el desarrollo y mantenimiento de los servicios propios de una cabecera comercial son la accesibilidad, la calidad del servicio y las características de los residentes. En este caso, el establecimiento de centros de servicios demostró ser «un vehículo clave para la mejora de los servicios rurales, que se basa en una colaboración entre la Countryside Agengy, a través de sus divisiones regionales y las agencias de desarrollo regional» (Ibid; 27).

Más recientemente, Swan, Selvaraj y Godden (2008) han llevado a cabo un estudio en el ámbito de los servicios de salud en las zonas rurales, con el fin de saber más acerca de su nivel de perifericidad, para utilizarlo como un indicador significativo que responda a las necesidades de los profesionales y servicios. El área de estudio fue el Highlands West escocés. Desarrollaron el indicador denominado «situación periférica clínica», compuesto por cuatro variables (densidad de población, número de pacientes en las listas del servicio, tiempo de desplazamiento hasta el hospital más cercano, y tiempo de desplazamiento hasta la sede administrativa sanitaria más próxima) convertidos mediante análisis factorial en términos de porcentaje de la varianza. El indicador propuesto representa la combinación de dos modelos y metodologías (modelos gravitacionales y tiempo/coste de desplazamiento como indicadores de accesibilidad). Según los autores, el desarrollo de este índice proporciona una herramienta para la planificación de servicios y para explorar la relación entre la periferia, los patrones de enfermedad y la calidad de los servicios ofrecidos.

También en el ámbito de la salud, existe un estudio realizado por el Department of Health, Social Services and Public Safety (2004) en Irlanda del Norte. El estudio aborda una comparación entre las zonas rurales, las no rurales, y el promedio total del Irlanda del Norte, en relación con la localización y el tiempo de desplazamiento al centro o servicio más cercano en las zonas rurales, a través del «tiempo promedio de acceso (minutos) y el tiempo promedio de acceso ponderado por necesidad (minutos)». Se utilizaron como variables de comparación los siguientes: farmacias, odontólogo, atención oftalmológica, atención primaria, guarderías, centros de día, residencias de ancianos, centros psiquiátricos, programas para el tratamiento de trastornos del aprendizaje, discapacidad física y sensorial de la aten- 
ción; hospitales con servicios de hospitalización, consultas externa hospitalarias, unidades de maternidad, servicios de urgencias, hospitales con servicio de salud mental y ambulatorios.

Por último, Hull (2005) llevó a cabo un análisis empírico de un caso de política integrada de movilidad urbana en Suecia, destacando la necesidad de políticas integradas a nivel local. Señaló una serie de fallos generales: la duplicación de procedimientos, el fracaso en la comunicación y la falta de responsabilidades claras. A continuación, desarrolló un modelo para la integración de las distintas políticas de movilidad y lo comparó con las prácticas de gestión de la movilidad en el Reino Unido.

\section{CONCLUSIONES}

A lo largo de los apartados previos se han puesto de manifiesto algunos aspectos y procesos que deben tomarse en consideración a la hora de desarrollar una planificación adecuada de los recursos disponibles y de las inversiones previstas en el ámbito de los SeIG. Es esencial conocer las necesidades y demandas reales de la población antes de implantar planes y programas que pueden no ser relevantes para los actores implicados en el desarrollo territorial. Se necesita una aproximación flexible a la interpretación de la naturaleza del territorio para entender las dinámicas de la diversidad rural. De este modo, emergerán multitud de elementos contextuales que influyen en la movilidad y la accesibilidad.

En línea con lo argumentado, se debe tener en cuenta, que Los SeIG pueden llegar a ser cruciales para el desarrollo rural, pero no constituyen auténticas fuerzas de cambio en sí mismos. Por definición, los SeIG son de interés general debido a su importancia para la producción y prestación de otros bienes y servicios, así como para el bienestar de los ciudadanos. Por tanto, estos servicios desempeñan un papel crucial para el desarrollo local, en general, y para el desarrollo de las zonas rurales, en particular. Sin embargo, muchos de estos servicios, ya sean proporcionados por las autoridades públicas o por proveedores de servicios privados, dependen de la demanda y, por ello, reaccionan a cambios económicos y sociales más generales. Por esta razón, los SeIG no pueden constituirse como impulsores de cambio, sino que dependerán de las políticas de desarrollo generales que se apliquen en cada caso.

Las principales conclusiones que pueden extraerse respecto a la naturaleza, procesos y futuro de los SeIG en Europa, tras los análisis realizados, son:

La accesibilidad es un concepto multidimensional que se refiere no solo a la distancia física sino que implica otras dimensiones complementarias: tiempo de desplazamiento (asociado a las condiciones morfológicas o climáticas, estado de las infraestructuras de comunicaciones, eficiencia de la planificación territorial, disponibilidad y estado de sistema de transporte público, etc.), coste económico (disponibilidad de vehículo privado, costes de transporte, etc.), factores socio-culturales (determinan la demanda o percepción de la necesidad de acceso a bienes y servicios), disponibilidad, elementos subjetivos relacionados con las condiciones físicas y psicológicas de los individuos, factores históricos que han condicionado una determinada configuración espacial que afecta a la disponibilidad y accesibilidad de bienes, servicios y empleo, y la orientación y eficacia de las políticas con impacto en la provisión y accesibilidad. Esta multidimensionalidad incrementa la complejidad de la problemática asociada a la provisión y acceso a los SeIG que, en el caso de las áreas rurales, resulta de especial relevancia para mantener un territorio organizado y equilibrado. 
A pesar de que muchas constituciones de países europeos reivindican el derecho a la igualdad de acceso a servicios básicos para toda la población con independencia de su lugar de resdencia, lo cierto es que la accesibilidad a los SeIG se ve dificultada para los residentes de las áreas rurales por diversos problemas relacionados con: (i) una densidad de ocupación del territorio más baja; (ii) el predominio de asentamientos poblacionales más pequeños y, con frecuencia, dispersos; (iii) el proceso de declive económico y demográfico en las zonas rurales menos accesibles; (iv) el rápido crecimiento y reorganización territorial en las áreas rurales accesibles; (v) el reducido tamaño de los mercados de trabajo locales, entre otros. Todas las tipologías de áreas rurales presentan problemas relacionados con la provisión y acceso a SeIG que son de diferente naturaleza según el tipo de área. En consecuencia, afectan a los residentes rurales de maneras distintas. Esta diversidad de situaciones plantea la necesidad de respuestas adaptadas a las diferentes realidades de la provisión y acceso a SeIG en las áreas rurales europeas.

Un buen número de residentes rurales, principalmente aquellos que pertenecen a grupos desfavorecidos o que no tienen acceso a vehículo privado (personas mayores, desempleados, mujeres, niños, personas con discapacidades, etc.) ven sus posibilidades de acceso restringidas a un pequeño conjunto de bienes, servicios y puestos de trabajo. Esta situación reduce sus posibilidades de elección, su libertad y, en última instancia, su calidad de vida. Por otro lado, la provisión de servicios e infraestructuras responde principalmente a criterios de ahorro y eficiencia. Los mercados rurales no alcanzan, en la mayoría de los casos, el umbral de masa crítica necesario para sostener muchos de los SeIG. El resultado es un ciclo de declive que reduce progresivamente los servicios y empleos y, en consecuencia, impulsa a la población a emigrar. Se requieren soluciones creativas de provisión para los servicios más sensibles (salud, alimentación), algunas de las cuales ya se practican con éxito en un reducido número de regiones y localidades europeas.

Los espacios rurales constituyen el hogar de un número creciente de nuevos residentes cuyas culturas, hábitos de consumo y patrones de movilidad difieren de los que poseen los habitantes rurales tradicionales. Estos nuevos residentes, principalmente de raigambre urbana, residen de forma temporal o permanente en el medio rural: inmigrantes de diversos orígenes (jubilados centro y norte-europeos, familias e individuos procedentes de países con menor nivel de desarrollo, etc.), nuevos residentes permanentes que se instalan en el medio rural accesible provenientes de ciudades y áreas metropolitanas cercanas, residentes temporales y vacacionales, etc. Estos colectivos tienen un impacto significativo sobre las condiciones de acceso a bienes, servicios y empleo. Por ejemplo, suelen mantener pautas de consumo urbanas con patrones de movilidad que implican desplazamientos más frecuentes a mayores distancias y por razones diferentes a los de los habitantes rurales tradicionales, y una cultura de la movilidad menos sostenible. A pesar de que se producen algunos efectos negativos (demandas diferentes, tensión inflacionista, etc.), su influencia es generalmente positiva y su presencia puede contribuir a contrarrestar los efectos del declive rural, incrementar el tamaño del mercado de trabajo local, y mejorar las condiciones de acceso a servicios y empleo mediante la mejora de la viabilidad de los sistemas de provisión.

En conjunto, a medida que aumenta la distancia disminuye la provisión y facilidad de acceso a los SeIG. Esta tendencia se ve reforzada por la evidencia empírica de que la distan- 
cia de acceso a los SeIG se ha incrementado durante los últimos 20 años y parece que esta tendencia seguirá incrementándose, principalmente en las áreas de difícil acceso. De ello se deriva que los SeIG tienden a concentrarse cada vez más en las áreas urbanas y accesibles, contribuyendo a incrementar los desequilibrios entre regiones rurales y urbanas, y entre los diferentes tipos de regiones rurales. Si bien el porcentaje de población afectada es pequeño, no puede decirse lo mismo del porcentaje de territorio afectado, lo que tiene implicaciones potenciales de gran importancia sobre la capacidad de una sociedad para mantener su territorio ordenado y «bajo control». Esto significa que, más allá del servicio social y del rendimiento económico que pueda producir, el mantenimiento de una estructura territorial equilibrada en lo que se refiere a provisión de SeIG tiene implicaciones ambientales y paisajísticas de primer orden.

El desarrollo de los SeIG se relaciona positivamente con el crecimiento económico y demográfico de las áreas rurales. En consecuencia, los SeIG forman parte del proceso de declive rural pero también del proceso de desarrollo rural. En todo caso, estas correlaciones no indican en qué medida el desarrollo o reducción de la provisión y acceso a SeIG son causa o consecuencia de los procesos de desarrollo o declive rural.

Como consecuencia de la emigración tradicional de población joven de las áreas rurales, la edad media es elevada, principalmente en las áreas rurales desfavorecidas y de montaña. Dado que el segmento de población de más edad es menos móvil y, al mismo tiempo, más dependiente de los SeIG (por ejemplo, de los servicios sanitarios), se genera un problema potencial dado que las áreas más envejecidas son, al mismo tiempo, las que registran un mayor descenso en la provisión y accesibilidad a los SeIG. En todo caso, la situación y las tendencias de desarrollo de los SeIG difieren notablemente, por lo que es necesario contrastar todos los argumentos previos con la situación particular de cada tipo de servicio.

Un mejor conocimiento de los factores y procesos que condicionan la provisión y acceso a los SeIG en áreas rurales proporciona los siguientes beneficios: en primer lugar, entender la diversidad de la problemática asociada a la accesibilidad en un mundo rural diverso; en segundo lugar, establecer una priorización estratégica de servicios públicos y privados de acuerdo con su relevancia para el mantenimiento del tejido social y económico en las áreas rurales; en tercer lugar, determinar el éxito y/o la necesidad de soluciones innovadoras para la provisión de SeIG en áreas rurales; en cuarto lugar, establecer procedimientos adecuados para implantar estas soluciones; por último, proponer métodos y procedimientos para desarrollar estrategias para resolver problemas reales y potenciales de exclusión social asociados a malas condiciones de accesibilidad a SeIG en áreas rurales.

De acuerdo con este razonamiento parece inevitable y justificado plantear una intervención pública dirigida a mejorar las condiciones de provisión y acceso a SeIG en áreas rurales. En el caso de las áreas rurales desfavorecidas y de difícil accesibilidad, la finalidad es asegurar la igualdad de oportunidades de acceso a SeIG en comparación con otras localizaciones más ventajosas. En las áreas rurales próximas, los retos pasan por contribuir a una organización territorial más racional y eficiente en un contexto de cambios acelerados que ponen en peligro los recursos naturales y culturales. En cualquier caso, una mejora en las condiciones de accesibilidad a estos servicios en zonas rurales contribuirá al objetivo de la igualdad de oportunidades y a reducir las disparidades regionales. Es, por tanto, lógico que algunos autores señalen a los problemas de accesibilidad como elementos fundamentales a 
resolver en las estrategias de inserción de las zonas rurales en la economía mundial (Silva Pérez, 2002).

La Unión Europea constituye uno de los entornos con una acción pública más evidente encaminada a lograr la cohesión regional y los principios de igualdad de oportunidades y equivalencia territorial, como lo demuestran diversas declaraciones desde el Tratado Fundacional hasta la Estrategia de Lisboa o el marco estratégico Europa 2020, formulados en varios documentos estratégicos (El Futuro del Mundo Rural (1987), la Estrategia Territorial Europea (1994), la Agenda 2000 y + 2000, los informes de cohesión, etc.) e implementados en múltiples políticas y programas cuyo objetivo es la cohesión social y territorial, y la reducción de las disparidades regionales.

La provisión y acceso a los SeIG son fundamentales para la política regional y de cohesión de la UE, en sintonía con el objetivo de un desarrollo territorial equilibrado. Sin embargo, los objetivos de «equivalencia territorial» e igualdad de oportunidades en relación a los servicios no dependen únicamente de la existencia de un determinado servicio, sino también de otros factores clave (Muscar, 2007) como la capacidad y la calidad de los equipamientos, su ubicación y área de influencia, o su accesibilidad. Una adecuada comprensión de estos factores permitirá identificar las carencias existentes y las necesidades de mejora.

\section{BIBLIOGRAFÍA}

ALGUACIL, J. (2006): Los equipamientos de proximidad como soporte para el desarrollo de derechos de la ciudadanía. http://www.ciudad-derechos.org/espanol/pdf/gb.pdf .

AUYDA, M.I., PINILLA, V. y SÁEZ, L. (2000): «El problema de la despoblación en Aragón: Causas, características y perspectivas». Boletín de la Asociación Demográfica Histórica, XVIII, I. Universidad de Zaragoza.

BANISTER D. y BERECHMAN J. (2000): Transport Investment and Economic Development, London. University College London Press.

CAMARERO, L.A. (1993): Del éxodo rural y del éxodo urbano. Ministerio de Agricultura, Pesca y Alimentación. Serie Estudios, no 81, 512 pp.

CHRISTALLER, W. (1933): Die zentralen Orte in Süddeutschland. Gustav Fischer, Jena.

CLIFTON, J. C., COMÍN, F., y DÍAZ-FUENTES, D. (2006): «Privatization in the European Union: Ideological, pragmatic, inevitable?», Journal of European Public Policy, Vol. 13 (5), pp. 736-756.

COM (1994) Europa 2000+. Cooperación para la ordenación del territorio europeo. Oficina de Publicaciones Oficiales de las Comunidades Europeas, Luxemburgo

COM (1997): Eurobarometer 47.0. Disponible en http://ec.europa.eu/public_opinion/archives/eb/eb47/eb47_en.htm

COM (2003) Green paper on services of general interest, disponible en http://eur-lex. europa.eu/smartapi/cgi/sga_doc?smartapi!celexplus!prod!DocNumber\&lg=en\&type doc=COMfinal\&an_doc $=2003 \&$ nu_doc $=270$

COM (2004a) Communication from the Commission to the European Parliament, the Council, the European Economic and Social Committee and the Committee of the Regions - White Paper on services of general interest, 12 Mayo 2004, Brussels, disponible en: http://ec.europa.eu/services_general_interest/index_en.htm 
COM (2004b) Una nueva asociación para la cohesión: convergencia, competitividad, cooperación. Tercer informe sobre la cohesión económica y social. Oficina de Publicaciones Oficiales de las Comunidades Europeas, Luxemburgo

COM (2004c) Eurobarometer 62.1 y 62.2, disponible en http://www.icpsr.umich.edu/icpsrweb/ICPSR/studies/4341

COM (2007) Crecimiento de las regiones, desarrollo de Europa. Cuarto Informe sobre la cohesión económica y social. Oficina de Publicaciones Oficiales de las Comunidades Europeas, Luxemburgo

COM (2008): Comunicación de la Comisión al Parlamento Europeo, al Consejo, al Comité Económico y Social Europeo y al Comité de las Regiones. Agenda social Renovada: Oportunidades, acceso y solidaridad en la Europa del siglo XXI, 2 de Julio de 2008, Bruselas.

COM (2008) Thinking about rural transport. Sustainable Rural accessibility - is it really possible?, disponible en http://www.ruralcommunities.gov.uk/publications/thinkingaboutruraltransportsustainableruralaccessibilityisitreallypossible

http://www.privatizationbarometer.net/

DEPARTMENT OF HEALTH, SOCIAL SERVICES AND PUBLIC SAFETY (2004): Equality and Inequalities in Health and Social Care in Northern Ireland: A Statistical Overview. Northern Ireland Statistics \& Research Agency.

DEPARTMENT FOR TRANSPORT (2006): Full guidance for local transport: $2^{\text {nd }}$ ed.,en http://www.dft.gov.uk/pgr/regional/ltp/guidance/fltp/fullguidanceonlocaltransport3657

DEREK, H., FARRINGHTON, J. y COPUS, A. (2002): Rural Accessibility. Scottish Executive Central Research Unit.

FARRINGTON, J. y FARRINGTON, C. (2005): «Rural accessibility, social inclusion and social justice: towards conceptualisation», Journal of Transport Geography 13, pp. 1-12.

GILG, A. (1983): «Population and Employment», in Pacione, M. (Ed.) Progress in Rural Geography. London, Croom and Helm, pp. 74-105.

HALDEN, D., J. FARRINGTON, AND A. COPUS (2002) Rural accessibility. Scottish Executive Central Research Unit report. Disponible en: http://www.scotland.gov.uk/ Resource/Doc/46922/0030639.pdf

HOTELLING, JH. (1931): The Economics of Exhaustible Resources, JPE.

HULL, A. (2005): «Integrated transport planning in the UK: From concept to reality». Journal of Transport Geography 13 (2005), pp. 318-328.

LABASSE, J. (1973): La organización del espacio. Elementos de Geografía aplicada. Instituto de Estudios de Administración Local.

MOSELEY, M.J. (1979): Accesibility: the rural challenge. Methuen, Londres.

MOSELEY, M.J. (2000): «Innovation and rural development: some lessons form Britain and Western Europe». Town Planning Review 71 (4), pp. 415-433.

MÚSCAR; E. (2008): Las necesidades básicas insatisfechas (NBI) y su relación con los equipamientos: salud y educación. Downloadable from http://www.ciudad-derechos.org/ espanol/pdf/gam.pdf

NOGUERA, J. y MORCILLO, L. (2012): «Analysis of the diversity of European Regions», en Copus, A. y Hörnström, L. (Eds.) The New Rural Europe: Towards Rural Cohesion Policy. Nordregio Reports 11. 
NUTLEY, S.D. (1992): Rural areas: the accessibility problem. Eds. Hoyle, B. and Knowles, R. Modern Transport Geography, Vol. Belhaven, London, pp. 125-154.

PALANG, H.; PRINTSMANN, A.; GYURÓ, E.; URBANC, M.; SKOWRONEK, E. y WOLOSZYN, W. (2006): "The forgotten rural landscapes of Central and eastern Europe», Landscape Ecology, Volume 21, Number 3, pp. 347-357.

PAROLIN, B., NICHOLS, M. y MCDOUGALL, W. (1994): «Modeling Rural Accessibility». Papers of the Austrasian Transport Research Forum 19, pp. 45-62.

PIKE, A.; RODRÍGUEZ-POSE, A. y TOMANEY, J. (2006): Local and regional development. Routledge, $310 \mathrm{pp}$.

POWE, N.A. AND SHAW, T. ET AL. (2004): «Exploring the current and future role of market towns in servicing their hinterlands: a case study of Alnwick in the North East of England». Journal of Rural Studies, 20, pp. 405-418.

ROSTAMI, S. (2005): Application of the transport needs concept to rural New South Wales: a GIS-based analysis. PhD Thesis. University of New South Wales. School of Built Environment. Downloadable from http://unsworks.unsw.edu.au/vital/access/manager/Repository/unsworks:772

SARKAR, A. y GHOSH, D. (2000): «Meeting the accessibility needs of rural poor». IASSI Quarterly, vol. $18, \mathrm{n}^{\circ} 4$.

SILVA PÉREZ, R. (2002): «Estrategias de inserción de las áreas rurales en la economía mundial. Una aproximación desde Andalucía». Boletín de la Asociación de Geógrafos Españoles, 33, pp. 103-131.

STOREY, P. y BRANNEN J. (2000): Young people and transport in rural areas. Joseph Rowntree Foundation.

SWAN, GM., SELVARAJ, S. y GODDEN, DJ. (2008): Clinical peripherality: development of a peripherality index for rural health services. In www.biomedcentral.com/content/ pdf/1472-6963-8-23.pdf.

VINSON, T. (2004): «Community adversity and resilience the distribution of social disadvantage in Victoria and New South Wales and the mediating role of social cohesion». Jesuit Social Services. Richmond.

WEBER, A. (1909): Teoría pura de la localización. 